\title{
A dependência da política: \\ Fernando Henrique Cardoso e a sociologia no Brasil
}

Afrânio Garcia Jr.

Em duas conferências proferidas em M unique em 1918, reunidas posteriormente em um só livro, M ax Weber opôs a vocação de cientista à de político, sobretudo no tocante às modalidades de acesso à profissão e aos requisitos em disposições mentais: “Em todo caso, as disposições que fazem de um homem um pensador eminente e um professor de universidade não são certamente as mesmas que poderiam fazer dele um chefe no domínio prático da vida, especialmente no domínio político" (Weber, 1959, p. 97). A diversificação do campo do poder, nas nações modernas, permite a autonomização de um pólo intelectual que não é mais subordinado aos imperativos das autoridades políticas, das autoridades religiosas ou do poder econômico. A passagem do universo das atividades intelectuais, particularmente no terreno da pesquisa científica, para o domínio das atividades políticas não se faz sem dificuldades e descontinuidades.

A eleição de Fernando $\mathrm{H}$ enrique $\mathrm{C}$ ardoso à presidência da $\mathrm{R}$ epública do B rasil parece contradizer a afirmação weberiana.Tanto mais que a condição de sociólogo foi apresentada durante toda a campanha eleitoral como prova de sua capacidade de afrontar o desafio da mundialização dosmercados e ao mesmo tempo combater a miséria crescente de parte considerável da população do país. A qualidade de sociólogo foi relembrada cada vez que quis pôr em relevo sua condição de intelectual, buscando se diferenciar de outros profissionais e especialistas da política cuja única preocupa 
1. Pollak demonstrou que o próprio Weber teceu comentários dia metralmente opostos sobre o papel do cientista social diante dos debatessobre osrumos do Estado, comparando os textos de 1918 com seu discurso de posse na cátedra de Economia Política da U niversidade deFriburgo cercade trinta anos antes (cf. Pollak, 1996, pp. 85114).

2. A shipóteses expres sas neste parágrafo visaram à sua discussão no seminário anual de Bourdieu na EHESS (1997). Em sessão dedicada a "Tradições nacionais das ciências sociais", fui convidado a refletir sobreo caso brasileiro. O scomentá rios de Bourdieu estimularam-meaaprofundar a reflexão e objetivar por meio de análises empíricas as rela ções entre sociologia e poder político, o que melevou a debruçar sobre a trajetória social e intelectual de Fernando $\mathrm{H}$ enrique $\mathrm{C}$ ardoso. Juntamente com o estudo da trajetória de C elso Furtado (Garcia Jr., 1998a eb), este exa me permitiu esboçar 0 escopo da pesquisa ção seria a preservação de seus mandatos eletivos. Tudo se passa como se, para ser reconhecido como homem de Estado, fosse necessário mobilizar a crença na ficção de ser um perito em todos os debates sobre o futuro da nação e seu peso na cena internacional. U m livro com uma entrevista sua, publicado no exercício do mandato, não se intitula 0 presidente segundo 0 sociólogo (1998), traindo claramente a pretensão de acumular os benefícios da legitimidade intelectual e os da legitimidade política?

De fato, esse caso de forma alguma parece constituir uma exceção ao preceito weberiano, diminuindo o valor da distinção entre a vocação intelectual e a de político ${ }^{1}$, muito menos algo que apenas possa ser explica do por "coisas que só acontecem no Brasil". 0 estudo da trajetória social de Fernando Henrique, particularmente do deslocamento posterior de seus investimentos e de seus recursos sociais, adquiridos como sociólogo no início de sua carreira profissional, para o campo político, abrindo acesso ao mandato presidencial, pode contribuir para a compreensão dos diferentes tipos de disposições e capitais sociais necessários ao exercício de cada um dos dois ofícios e para especificar as condições da autonomização das ciências sociais diante do universo político.

Foi a natureza mesma da relação entre campo político e condições de existência das ciências sociais no Brasil que variou em larga medida nos últimos quarenta anos: paradoxalmente, durante a ditadura militar foram criados novos centros de pesquisa e programas de pós- graduação, que permitiram a multiplicação de monografias e de estudos empíricos inovadorese de alta qualidade, em diálogo constante com a literatura internacional mais avançada, enquanto o retorno às normas democráticas se fez acompanhar de uma perda de fôlego em várias frentes de trabal ho abertas, sobretudo se considerarmos os estudos de grupos de origem popular na cidade e no campo. Talvez esse desenvolvimento das ciências sociais sob condições políticas extremamente adversas se deva ao fato de muitos terem se consagrado à pesquisa empírica apenas por falta de possibilidades de seguirem carreiras políticas ou na alta administração. 0 fato é que, após a liberalização do espaço público, uma parte considerável dosesforçosentão consagrados à pesquisa e ao ensino se deslocou para a disputa pelos postos de direção do Estado, sob a forma quer de cargos eletivos, quer de cargos de confiança na alta administração².

U m dosfocos mais significativos dos debates públicos, quanto ao cará ter precário da autonomia das ciências sociais no Brasil, reside nos usos legítimos da palavra sociologia. 0 sentido dominante desde o fim do século 
XIX, utilizado por autores que também tinham pretensões a carreiras políticas, em sua maioria bacharéis em $D$ ireito de classe alta, atribui a essa disciplina um dos primeiros lugares na hierarquia dos saberes de Estado e a reserva aos escritores que visam a discutir os destinos da nação. Completamente diferente é o sentido inovador do ofício de sociólogo pregado por Florestan Fernandes, mestre de Fernando $\mathrm{H}$ enrique e seu orientador de doutorado na USP, explicitado no título de um de seus principais livros, Fundamentos empíricos da explicação sociológica, de 1967.

\section{Grande herdeiro político}

Contra a idéia corrente, e muito difundida pela imprensa, de uma passagem recente e custosa do mundo intelectual à política, como parece ter sido o caso do escritor peruano $\mathrm{M}$ ario Vargas Llosa, candidato derrotado para a presidência daquele país, foi o próprio Fernando $\mathrm{H}$ enrique quem exprimiu, em entrevista à revista $V$ eja, sua familiaridade com a política, atividade que se inscreve em experiências de infância:

R oberto Toledo: $\mathrm{N}$ o livro em que conta sua experiência de candidato à presidência do Peru (Peixena água), Vargas Llosa mostra como, progressivamente, foi criando aversão à atividade política. Entre outras coisas, ele diz abominar o que chama de "artes evasivas" dos políticos - as conversas não afirmativas, protelatórias. A parentemente, diante de Vargas Llosa e Fernando $\mathrm{H}$ enrique $\mathrm{C}$ ardoso, dois intelectuais seduzidos pela política, está-se diante de casos similares. M as, ao que parece, a rotina da atividade política, que tanto desagradava Vargas Llosa, em Fernando $\mathrm{H}$ enrique causa o efeito oposto: fascina. 0 livro de Vargas Llosa seria excelente leitura, então, para saber como não é Fernando $\mathrm{H}$ enrique $\mathrm{C}$ ardoso. Está certo?

FHC: Está certo. E isso tem várias origens. Primeiro fui criado numa família afeita à política. Então, desde menino, bem menino mesmo, com oito ou nove anos - meu pai era uma pessoa muito aberta, muito democrata -, eu participava das conversas, ou assistia às conversas. Já na casa de minha avó era assim: depois do almoço ou do jantar - mais do jantar - começava a discussão política. Havia muita briga entre eles. M eu pai era militar e meu avô também. T inham participa do de muitos episódios da história do Brasil. O utro dia li um artigo do Sarney mencionando um jovem tenente - ou alferes, como diziam na época - que tinha proposto fuzilar o imperador. Eu disse: “É o meu avô". Há um quadro clássico de três oficiais levando ao Imperador a ordem de banimento. U m é meu avô (Toledo, 1998, pp. 339-340). atual sobre a"circulação internacional de universitários". 
Sua geneal ogia, confeccionada nas várias obras de caráter hagiográfico aqui citadas, atesta os indicadores de elevada origem social e a partici pação direta de seus ascendentes nos eventos mais relevantes da história do B rasil contemporâneo. Seu bisavô foi chefe do Partido Conservador de Goiás durante o Segundo Império, eleito deputado por várias legislaturas, foi senador e presidente de província. Seu avô, ainda jovem oficial do Exército, participou ativamente da queda da M onarquia e da proclamação da R epública, como revela o trecho citado, o que Ihe valeu ser ajudante- deordens de Floriano Peixoto, 0 " marechal de ferro", e chegar a morar, junto com seu pai, no Palácio do Itamaraty, residência oficial do presidente. Findou sua carreira como marechal, mas não sem antes participar do levante de 1922 e, juntamente com o ex-presidente H ermes da Fonseca, ter sido preso por esse motivo.

$\mathrm{O}$ pai de Fernando $\mathrm{H}$ enrique também seguiu a carreira militar e participou das revoltas tenentistas de 1922 e 1924, que culminaram na revolução de 1930 e na condução de G etulio Vargas ao poder central. U m dosfuturos ministros da G uerra do Estado N ovo varguista, Eurico G aspar D utra, presidente da R epública depois da derrubada de Vargas em 1945, havia sido ajudante-de-ordens de seu avô, seu pai fora oficial de gabinete do ministro Góes M onteiro em 1934, e seu tio, A ugusto Inacio do Espirito Santo C ardoso, foi ministro da Guerra de Vargas durante o governo provisório de 1931 a 1933. Seu círculo familiar maisdireto esteve no palco dosacontecimentos da revolução de 1930, mas houve também participações em campos antagônicos no levante de 1932 em São Paulo. Eles estiveram próximos também dos oficiais que mudaram o perfil e a composição do Exército brasileiro a partir dos anos de 1930. A pós deixar o Exército em

3. 0 estudo da hereditariedade na política brasileira vem sendo feito, de forma inovadora e empiricamente sólida, por Letícia Canedo (2002), cadernos nos quais aparece também o comentário crítico de Jean Pierre Faguer, que enfatiza a riqueza dessa linha de investigação históricae sociológica. 1945, como general, seu pai exerceu a advocacia - havia se diplomado em D ireito nosanos de 1930 - e seu engajamento político em causas nacionalistas permitiu sua eleição para deputado federal por São Paulo em 1954.

Sem sombra de dúvida, a infância e a adolescência de Fernando H enrique foram povoadas de relatos dosfamiliaresque participaram dosgrandes eventos da história republicana brasileira. 0 que a imensa maioria de sua geração soube por meio de manuais de história ou de relatos de imprensa, ele conheceu por testemunhas e participantes diretos dos acontecimentos. Para ele, de fato, "esses personagens [... ] não eram de ficção. Eram pessoas" (Toledo, 1998, p. 342). Tanto os relatos de seu pai como o culto das tradições familiares por sua avó paterna incutiram em Fernando H enrique um forte sentimento de hereditariedade da competência política, 
o que o levou a postular: "M eu pai era político. Essa dimensão está no meu sangue" (Leoni,1997, p. 44).

\section{Formação como sociólogo e início da carreira}

$N$ ascido em 1931 no Rio de Janeiro, primogênito da fratria, fez 0 curso primário entre $\mathrm{R}$ io de Janeiro e São Paulo, conforme exigido pelo trabalho de seu pai. Dispôs de professora particular de francês, algo comum às famílias abastadas e cosmopolitas do Brasil na Primeira R epública, como comprova também o caso de Gilberto Freyre. Fez os estudos secundários em São Paulo, em um colégio do bairro de Higienópolis freqüentado por descendentes de famílias afluentes, bairro em que reside até hoje. Em 1949, presta concurso para duas faculdades da U SP: não é aprovado em latim, na tradicional Faculdade de D ireito, mas entra para a Faculdade de Filosofia, Ciências e Letras, fundada com a colaboração da missão francesa. Como bem analisa I rene C ardoso (1982) ${ }^{4}$, a criação dessa faculdade, que possibilitou a fundação da U SP em 1934, faz parte de um conjunto de estratégias da elite política de São Paulo que, sentindo perder grande parte do poder federal com a ascensão de Vargas e sua coligação com M inas $G$ erais e os estados nordestinos, de menor influência no plano nacional, e vendo-se alijada dos principais núcleos de decisão após a derrota de 1932, buscou recuperar, por meio dos investimentos em ciência e cultura, a nítida hegemonia nacional durante a "R epúblicaVelha", subtraída pela força das armas. 0 apelo ao que havia de mais moderno no mundo internacional foi grandemente reforçado pela intenção paulista de demarcar-se como estado onde predominaria um espírito liberal e cosmopolita, o que transparece na utilização do francês e do inglês nos cursos, já que só os docentes alemães parecem ter se sentido compelidos a ministrar os ensinamentos em português.

Seu principal professor foi Florestan Fernandes, um descendente de imigrantes portugueses órfão de pai, de origem modesta, que só pôde completar seus estudos secundários graças a exames supletivos e que muito teve de se esforçar para freqüentar os professores franceses da Faculdade de Filosofia, os pesqui sadores norte- americanos ligados à “E scola de $\mathrm{C}$ hicago", como Donald Pierson, e os antropólogos alemães, como seu orientador H erbert Baldus, recrutados pela rival Escola de Sociologia e Política. M uitas vezes Florestan exprimiu a dificuldade, para um estudante vindo das classes populares, de entrar no seleto mundo da nova elite inte-
4. Ver nessa mesma obra o prefácio de Alfredo Bosi. A configuração das missões es trangeirasna fundação da U SP e seus efeitos foram estudados em M iceli (1989).Ver ainda M iceli (1981) para análise da relação entre reconstrução do Es tado nacional a partir de 1930 e autonomização do campo intelectual brasileiro. 
5. U ma análise da formação intelectual de Florestan Fernandes pode ser vista em $M$ azza (2003). A proximidade distante de seus colegas brasileiros de origem social superior é analisada, com grande sensibilidade, por Pontes (1998).

6. M ayo (1997) demonstrou como aU nes co, criada apóso fim da Segunda Guerra M undial, buscava um laboratório de "tolerância racial" que servisse de contraponto paraanãoinevitabilidade de massacres justificados por racismo, como o perpetrado contra osjudeus na Europa. Tal a razão daescolhado Brasil, que conhecera a revaloriza ção da mestiçagem nos anos de 1930. lectual, representada grandemente pela pouca familiaridade com as línguas estrangeiras 5 . A precocidade em línguas estrangeiras, como ressaltam os estudos de sociolingüística, é um dos privilégios sociais dos que "tiveram berço" , masque aparece como um dom ou talento suplementar a atestar a superioridade ou "excelência" dos indivíduos de origem elevada. 0 investimento apaixonado nas tarefas intelectuais e o espírito meritocrático, bem como a busca da integração de tradições tão diferenciadasquanto as ensinadas pelosjovense brilhantes professores estrangei ros, cuja diversidade de modo algum se reduz às suas origens nacionais (fato patente em suas obras ulteriores), estão entre as características da trajetória intelectual de Florestan Fernandes. I sso demonstra tanto o investimento extra de fato exigido dosque alargam o perfil sociológico de estudantes potenciais como a possi bilidade que a universidade pública abria para a entrada de filhos das classes populares. Embora ressal tasse o alto custo psicológico de seusinvestimentos para poder acompanhar os professores estrangeiros e a literatura que introduziam, é notável que Florestan Fernandes tenha sempre se caracterizado por uma ligação constante com o universo internacional das ciências sociais, o que se revela tanto por seus livros baseados em pesquisa de campo com R oger Bastide como por suas tentativas reiteradas de integrar os aportes teóricos de Émile D urkheim, M ax Weber e K arl M arx.

Fernando H enrique $\mathrm{C}$ ardoso e seu colega $\mathrm{O}$ ctavio I anni iniciaram suas carreiras de pesquisadores sob a direção de Florestan Fernandes - cujas pesquisas so bre a condição social dos negros descendentes de escravosem São Paulo foram fruto do convite insistente de R oger Bastide e do financiamento da U nesco - , examinando as relações raciais nas cidades do Sul do país, fortemente marcadas pela imigração européia do fim do século $X \mid X^{6}$. A mbos fizeram suas teses so bre o legado das relações entre senhores brancos e escravos (C apitalismo e escravidão no Brasil meridional, de Fernando H enrique, de 1962, e A smetamorfoses do escravo, de lanni), tema que, a partir de 1933, com a publicação de C asa-grande e senzala, de G ilberto Freyre, passou a figurar entre as questões centrais do campo intelectual brasileiro. O s estudossob a direção de Florestan Fernandesvão mostrar que a industrialização e a modernização que a acompanha exacerbavam, e não diminuíam, os preconceitos raciais (M ayo, 1997). 0 interesse pela pesquisa na região sul, em cidades que conheciam forte crescimento industrial desde os anos de 1930, era tanto maior pelo fato de ser a região receptora de grande contingente de "brancos" de origem européia que não se identificavam com a fração da elite descendente dos senhores de escravos e/ ou da 
oligarquia agrária. 0 conjunto de trabalhos realizados sob a égide de Florestan Fernandes, e que faziam largo uso dos novos métodos de pesquisa em ciências sociais aplicados nos EstadosU nidose na Europa, assegurou 0 prestígio da "escola de sociologia de São Paulo" e destronou Gilberto Freyre da posição de líder inconteste das ciências sociais brasileiras. D ata dessa época a tentativa de reduzir 0 aporte de Gilberto Freyre apenas às situações nordestinas, como se $\mathrm{C}$ asa-grande e senz ala expressasse unicamente um discurso sobre a grande plantação canavieira da zona da mata nordestina, e não so bre toda a realidade brasileira. Prova da eficácia dessa estratégia de concorrência intelectual é que muitos círculos nem se lembram que o livro de Freyre restrito ao âmbito regional é $\mathrm{N}$ ordeste, publicado em 1936. A supremacia da"nova sociologia" praticada em São Paulo foi ainda mais efetiva por se referir ao pólo moderno de uma nação em desenvolvimento, em oposição a um $\mathrm{N}$ ordeste em nítido declínio.

Estudante jovem e promissor, Fernando $\mathrm{H}$ enrique tornou- se assistente da Faculdade de Economia da U SP, antes mesmo de concluir a licenciatura, com apenas 21 anos, cargo que acabou sendo perdido por disputascom a titular da cátedra. Logo depois, no entanto, um concurso abriria as portas para um cargo permanente na U SP. Fernando H enrique havia se tornado assistente de R oger Bastide assim que concluiu sua licenciatura, em 1953; quando Bastide resolve retornar a Paris, para ingressar na atual EHESS, Florestan Fernandes assume seu cargo e Fernando H enrique passa à condição de primeiro assistente. Assim que foi nomeado, elegeu-se para 0 Conselho U niversitário daU SP, cargo que, ocupado em início de carreira, parece ser um bom índice do capital social que conseguia mobilizar.

Seu pai fora eleito deputado federal graças a uma aliança entre os trabalhistas e os comunistas de São Paulo. Ao lado dele, Fernando H enrique participou ativamente da campanha pelo monopólio estatal do petróleo e pela criação da Petrobras. Pai e filho participaram das inúmeras mobilizações e campanhas nacionalistas dos anos de 1950 e início da década seguinte, momento marcado por intensos debates sobre as modalidades de construção política, econômica e cultural da nação e sobre os meios de enfrentar os males do "subdesenvolvimento". M ilitante desde 0 Colégio São Paulo, no qual cursara o secundário, suas atividades políticas fizeram que aceitasse o cargo de editor da revista do Partido Comunista destinada aos intelectuais - Problemas - e de membro do conselho editorial da revista marxista $\mathrm{F}$ undamentos, fundada por $\mathrm{C}$ aio Prado Jr. e editada pela Brasiliense. 
Sem dúvida seus investimentos profissionais no início da carreira estiveram concentrados nas atividades universitárias, o que no entanto não 0 afastavam necessariamente da carreira política. Terminada a tese de doutorado sobre a escravidão, Fernando $\mathrm{H}$ enrique realizou uma pesquisa por questionário sobre as atitudes e visões dos industriais brasileiros quanto ao futuro da economia, analisando também o papel atribuído ao Estado na regulação do setor econômico. Essa pesquisa, que mobilizava as contribuições da sociologia empírica européia e norte-americana, tinha por objeto uma das questões centrais nas polêmicas entre os vários grupos de esquerda: a "burguesia nacional" seria capaz de dar origem a um projeto de desenvolvimento original e de promover a emancipação do país?

0 marxismo constituiu, em certa medida, um sinal distintivo do jovem sociólogo de São Paulo. Ainda nos anos de 1950, quando JoséA rthur Gianotti volta da França após concluir seu doutorado, um grupo de jovens professores e estudantes decidiu se reunir para ler 0 capital, de $M$ arx. Esse grupo, do qual faziam parte $\mathrm{O}$ ctavio Ianni, $\mathrm{R}$ uth $\mathrm{C}$ ardoso, R oberto Schwarz, M ichael Lowy e outros, teve um papel decisivo na discussão dos projetos de pesquisa da nova geração. Florestan Fernandes, que nunca foi convidado a participar do grupo, encarou a iniciativa como um meio de osjovens pretendentes se apresentarem como pioneiros ou ao menos como nova vanguarda intelectual. A supremacia do marxismo, como teoria de referência, permitia desqualificar simultaneamente a bibliografia transmitida pelos membros da missão francesa e os esforços teóricos de Florestan Fernandes, acusado de ecletismo.

Por outro lado, foi a criação do Centro de Sociologia Industrial e do Trabalho (C esit), graças à iniciativa de Alain Touraine, professor convidado da U SP em 1961, que possibilitou o encaminhamento das investigações sobre os pontos de vista dos industriais e dos operários de São Pau-

7. Parao período 19531964, pude beneficiarme do projeto ainda não concluído de José Sérgio Leite Lopes (1990) e das inúmeras entrevistas efetuadas na França e no Brasil.Ver também Lopes (2003, pp. 169-178).
107. 0 centro foi dirigido por Fernando H enrique de 1962 a 1964. N esse mesmo período, A lain Touraine o convida para ir a Paris, no inverno de 1962-1963, o que permite a elaboração de sua tese de livre docência, defendida na U SP em 1963. A relação entre Fernando H enrique e Alain Touraine espelha os relacionamentos e as curtas estadias do sociólogo no exterior: em São Paulo, ele trabalhou sob a direção dos jovens pesquisadores franceses que marcaram o panorama das ciências sociais internacionais nos anos de 1950 e 1960, primeiro como assistente de R oger B astide, depois como braço direito deAlain Touraine; foi também um dos personagens principais do comitê de recepção a Jean-Paul Sartre e Simone de 
Beauvoir em sua visita à A mérica Latina, em setembro de 1960, após 0 apoio prestado à revolução cubana, o que levou Sartre a escolhê-lo como seu tradutor no Brasil. Assim, Fernando $\mathrm{H}$ enrique não teve necessidade de longas estadias no estrangeiro para familiarizar-se com as correntes de pensamento vigentes no campo internacional das ciências sociais ${ }^{8}$. Essa promissora carreira seria no entanto bloqueada pelo gol pe militar de 1964, que forçou seu exílio.

\section{Consagração internacional do sociólogo e retorno sob o regime militar}

O exílio permitiu a Fernando $\mathrm{H}$ enrique $\mathrm{C}$ ardoso consagrar-se a seus trabalhos de pesquisa, estender seu campo de conhecimento a toda a América Latina e ser convidado para estadias em instituições de grande prestígio internacional, como o Instituto de EstudosAvançados de Princeton ou o Collège de France. A inda antes de chegar ao $C$ hile, recebeu 0 convite do sociólogo espanhol José M edina Echavaria, diretor do ILPES, centro de pesquisas criado pela O N U em Santiago, para ocupar a cátedra de Sociologia do Desenvolvimento. 0 exílio levou- 0 a participar direta mente dos debates sobre as tranfformações do campo do poder naAmérica Latina e sobre seus efeitos econômicos e sociais. A teoria da dependência, que Ihe assegurou notoriedade internacional, foi concebida durante esse período, em colaboração com o sociólogo chileno Enzo Falleto (1979)9. Tanto no Brasil como no exterior, as investigações conduzidas por Fernando $\mathrm{H}$ enrique visavam essencialmente a analisar as representações de industriais e homens de negócios da América Latina, e sobretudo sua relação com a evolução do Estado. 0 exílio no $C$ hile, além de permitir 0 conhecimento da elite latino-americana - I sabel Allende trabalhou sob sua direção - , tornou possível voltar a Paris como professor convidado da U niversidade de $\mathrm{N}$ anterre, graças a uma nova intervenção de Alain Touraine. D urante essa estadia aproveitou para redigir a análise das investigações realizadas no ILPES e preparou sua tese destinada ao concurso da cátedra de Ciência Política na U SP, o que abreviaria seu exílio.

0 retorno à U SP, no entanto, teve curta duração: a instauração do AI5, em 13 de dezembro de 1968, foi acompanhada da demissão da função pública de professores e pesquisadores progressistas, do afastamento de estudantes e da instauração duradoura da tortura como técnica de neutra lização dos adversários do regime militar. A criação de um novo centro de pesquisas (C ebrap), com o financiamento da Fundação Ford, permitiu
8. A comparação com o itinerário profissional do economista Celso Furtado, dez anos mais velho, é bastante ilustrativa: de uma origem social e geográfica bem maismodesta que Fernando Henrique, foi graças à viagem à Europa, como oficial das tropas brasileiras durante a Segunda GuerraM undial, seguida por estudos doutorais na França, abrindo o caminho para um cargo na C epal em Santiago, que Furtado se dotou dos capitais necessários para sua entrada no campo político, marcada pela criação da Sudene e do M inistério do Planejamento. Perseguidosem 1964, os doisse encontrarão em Santiago do Chile. Cf. Garcia)r. (1998a, pp. 52-61; 1998b, pp. 123-132).

9.U ma excelente apresentação das questões analisadas pela "teoria da dependência" e seu contexto de elaboração está em Love (1996). 
aos pesquisadores e professores em ciências sociais, expulsos das instituições universitárias, prosseguirem as atividades de pesquisa sem abandonar o país. C omo demonstram Y ves D ezalay e B ryan Garth (2002), uma parcela da elite dominante dos $E$ stados $U$ nidos apoiou material mente al guns adversários dos militares, em particular cientistas, com receio de que a adesão à luta armada fosse ainda mais ampla. 0 apoio da Fundação Ford contribuiu para pôr em evidência os trabalhos ligados à pesquisa e ao ensino de ciências sociais, com a criação em escala inédita de institutos como o Cebrap, o C edec e o Idesp. N o R io de Janeiro, o apoio da Funda ção Ford tornou possivel a criação dos programas de pós-graduação em C iência Política no I uperj e em A ntropologia Social no M useu N acional. A diversificação das disciplinas, definindo novas modalidades de investigação empírica e a integração de pesquisadores a redes internacionais, deu alento às práticas de reconversão por parte de jovens estudantes e intelectuais que ficariam condenados ao silêncio. 0 C ebrap, sob a direção de Fernando Henrique, impôs-se então como pólo dominante na condução dos debates científicos em escala nacional.

Além de diretor do C ebrap, Fernando H enrique tornou-se, nos anos de 1970, um dos elos principais para o qual convergiam as mais diversas, e até mesmo antagônicas, forças políticas. $0 \mathrm{~s}$ antigos liberais, reagrupados no único partido de oposição tolerado pelosmilitares- o M D B, presidido por U lysses G uimarães - solicitaram a Fernando H enrique e ao C ebrap a redação de um novo programa a ser defendido pelo conjunto das oposições. A pesar de U lysses Guimarães ser um antigo amigo do pai de Fernando $\mathrm{H}$ enrique, foi durante o período mais negro do regime militar que os dois se aproximaram politicamente. R essalte-se que a I greja católica, que constituíra em 1964 um dos sustentáculos das forças que legitimaram 0 gol pe, passa a tomar distância dos generais em virtude da prática sistemática da tortura, fazendo progressivamente "uma opção preferencial pelos pobres". N esse contexto, o cardeal de São Paulo, dom Paulo Evaristo Arns, também solicitou ao C ebrap a elaboração de um diagnóstico sobre a degradação das condições de vida das camadas mais pobres de São Paulo, face oculta da aceleração do crescimento econômico, o que deu origem ao livro São Paulo, cresdimento e pobreza, de 1976, com prefácio do cardeal e no qual se explicitava a relação da investigação sociológica sobre os desprovidos de recursos, materiais e culturais, com as novas comunidades eclesiais de base. Assim, 0 engajamento de Fernando $\mathrm{H}$ enrique em atividades de reativação das asso ciações científicas e profissionais dos mais variados tipos 
(como SBPC , OAB, ABI , SBS, ABA), configurando a"mobilização da sociedade civil", tranformou- 0 em um dos líderes de uma intelectualidade interessada em se desfazer da tutela militar, preservando o pluralismo interno. Ele acumula então o prestígio de sociólogo inovador e de um dos líderes da frente de oposição política à ditadura militar. $\mathrm{N}$ o final dos anos de 1970, com a liberalização do espaço público após a assinatura da lei de anistia, de 1979, a sua volta à cena política torna-se visível.

\section{A carreira política na década de 1970}

0 investimento de Fernando $\mathrm{H}$ enrique na política torna-se mais nítido nos anos de 1970. C om a redação do programa do M DB, transformase em um dos maiores interlocutores de U lysses Guimarães, figurando como conselheiro privilegiado nos momentos de confronto com o regime. A greve dos metalúrgicos de São Bernardo em 1978, que projetou Lula e abriu as portas para o retorno dos movimentos sociais ao primeiro plano do espaço público, demonstrou que havia muitas outras forças políticas, além dos antigos políticos liberais formados antes de 1964. Por medo de uma derrota flagrante nas urnas, os oficiais militares de alta patente implantaram as sublegendas nos partidos, manobra que acomodava divergências entre os aliados dos militares e somava os votos de todos. A sublegenda permitiu uma diversificação nas oposições, e foi assim que Fernando H enrique se candidatou ao Senado em 1978, em sublegenda que somava seus votos ao do democrata cristão Franco M ontoro, mas que também permitia as diferenciações de programas políticos. Essa eleição apresentou ainda a vantagem para Fernando $\mathrm{H}$ enrique de poder conduzir uma campanha eleitoral sem se preocupar com as chances de vitória; graças a ela, ele se tornaria senador quando $M$ ontoro se candidata a governador, em 1982. D esde então todas as atividades de Fernando H enrique atestam a máxima concentração de esforços na atividade política: a produção de análises sociológicas ou de ciência política, sob a forma de monografias ou ensaios teóricos, é interrompida em 1978. A partir dessa data seus escritos ganham um novo tom, o de um político preocupado em defender suas tomadas de posição, em justificar suas alianças e em buscar ampliar suas chances eleitorais em um espaço que se diversifica.

$D$ iferentemente de muitosintelectuais que tentaram se iniciar na atividade política, ou voltar a ela, as estratégias eleitorais de Fernando H enrique mostram a racionalização da acumulação do capital político, partindo 
da consolidação de posições locais até atingir os cargos mais relevantes no âmbito nacional. Em 1985, apresenta-se como candidato a prefeito de São Paulo; a derrota, no entanto, não teve sobre ele o mesmo efeito dissuasivo que se verifica em muitos intelectuais, que não mais se apresentam à concorrência eleitoral. A análise da carreira política de Fernando H enrique certamente ultrapassa o escopo deste artigo, mas cabe assinalar que, desde o retorno das franquias democráticas, ele se tornou um político de relevo no plano estadual, um ministro potencial de todos os presidentes que 0 precederam, além de um dos parlamentares mais influentes na A ssembléia C onstituinte de 1988. N o governo de Itamar Franco, passou de ministro das $R$ elações Exteriores para ministro da Fazenda, com a responsabilidade de implantar um plano de estabilização monetária - o Plano R eal -, cuja implementação escalonada no tempo assegurou sua primeira eleição presidencial, ainda que a vitória no primeiro turno dependesse da aliança com o PFL, composto em grande parte pelas oligarquias nordestinas cujo brasão político adquirira novo brilho durante o regime militar.

Próximo dos pretendentes à renovação em grande escala do espaço público até 1979 , distanciou-se já nessa época dos líderes sindicais, como Lula, e dos colegas universitários que não dispunham de outro capital político que o obtido por meio da militância. $N$ ote-se que, após contribuir para a consolidação da idéia de um partido de trabalhadores, o que pode ser seguido pelas suas intervenções nos jornais de oposição à ditadura, como 0 pinião e M ovimento, não acompanhou seusantigos colegas da U SP, nomes emblemáticos das ciências sociais paulistas como Antonio C andido, Sérgio Buarque de $\mathrm{H}$ olanda, M aria I saura Pereira de Q ueiroz, Florestan Fernandes, 0 ctavio I anni, entre outros, na criação do PT, preferindo continuar seu itinerário em companhia daqueles que constituíram seus capitais políticos antes de 1964 ou na época do regime militar. Durante a campanha das diretas, suas posições aproximam-se sistematicamente dos moderados, distanciando-se da grande maioria dos universitáriose artistas. 0 bjetivamente, deslocou-se ao longo dos anos de 1980 e já muito antes das eleições de 1994, quando se confrontou com Lula e uma frente das oposições de esquerda, em direção ao centro e à direita.

\section{0 presidente secundado pelo sociólogo: qual sociologia?}

Esta rápida consideração do trabalho sociológico e da carreira política recente de Fernando $\mathrm{H}$ enrique $\mathrm{C}$ ardoso, que sem dúvida al guma exi- 
giria desenvolvimentos mais extensos, permite ao menos constatar que as disposições e os capitais mobilizados para abrir o caminho para a presidência da R epública não são de forma alguma os mesmosque aqueles empregados para construir os trabalhos sociológicos que asseguraram seu prestígio científico. 0 exame de suas publicações constitui 0 indicador mais nítido da política como carreira escolhida nos últimos 25 anos: se todas as obras anteriores a 1978 mostram uma preocupação constante com a constituição do material empírico que permita demonstrar as teses sociológicas sustentadas pelo autor, as publicações do período posterior limitam-se a reunir todos os argumentos capazes de justificar as tomadas de posição e as ações no campo político. $\mathrm{N}$ ão se trata aqui de sublinhar o caráter ideológico desses escritos, mas de entender que eles estão a serviço de outro objetivo que não o de dialogar com seus pares, cientistas sociais. Seguramente não foi graças aos seus esforços intelectuais que Fernando $\mathrm{H}$ enrique abriu o caminho de seus sucessos eleitorais; como a entrevista citada no começo deste artigo assinala, a maior parte do tempo do mandato presidencial foi consagrada a assegurar a confiança de eventuais aliados políticos e a reforçar suas chances eleitorais, como todo especialista da política.

Em livro editado a partir de um diálogo com o ex-presidente português M ário Soares, Fernando H enrique reafirma que a política o "fascina" e lhe proporciona "realização pessoal", motivos que o levam a usar todos os seus atributos internalizados como professor e pesquisador como recursos do "jogo político" (C ardoso e Soares, 1998, p. 53). Para compreender a rápida ascensão de Fernando $\mathrm{H}$ enrique à mais alta magistratura, é de pouca valia conhecer os modelos de análise que elaborou e as teorias que adotou em sociologia; mas é indispensável conhecer as redes sociais que deram significado e substância à sua atividade de sociólogo, pois foi a mobilização dessas redes, com outros fins que a produção do conhecimento, que tornaram possível sua carreira política. A s duas conferências de $M$ ax Weber citadas no início deste artigo, proferidas em tempos de fim da Primeira Guerra M undial, momento de enorme desencantamento com o mundo da política na Europa, demonstram a relevância de se estudar a concorrência entre os especialistas da produção do conhecimento, sem assimilá la aos mecanismos de concorrência entre os especialistas da política; os três livros publicados por ou sobre Fernando $\mathrm{H}$ enrique durante o mandato presidencial parecem constituir a melhor prova da pertinência da proposição de $M$ ax Weber. 
10. Luiz de $\mathrm{C}$ astro Faria (2002, pp. 99-101) sistematizou recentemente seu trabalho e suas reflexões sobre a obra de 0 liveiraViannae ahistóriasocial de sua recepção. Vale a pena destacar a análise do intelectual como "Guia Lopes" da nação (metáfora extraída de A retirada da laguna, de Taunay).
Situado na interseção do campo das ciências sociais - que se ampliava e se diversificava desde o início dos anos de 1970, com a nova amplitude conquistada pela antropologia social e pela ciência política - com o campo político, ele buscou colocar todo o prestígio adquirido como sociólogo a serviço de suas novas atividades políticas. Se Fernando H enrique pôde herdar de seu pai relações de confiança e de prestígio com políticos como U lysses Guimarães e Franco M ontoro, isso se deveu à frente de oposições ao regime militar e à sua posição de mediador entre cientistas e políticos. Seu afastamento da comunidade científica manifestou-se ainda por meio dos objetos e das maneiras de tratar as questões consideradas "sociológicas" , o que 0 aproxima da utilização da sociologia praticada pelos juristas consagrados como "pensadoressociais" durante o período de 1920 a 1960, quando pretendiam ter o monopólio da discussão sobre os destinos da naçãa ${ }^{10}$. Se a sociologia dispunha então de absoluta primazia sobre todas as ciências humanas e sociais, inclusive a história, é porque a retórica ensaísta predominava, excluindo das práticas disciplinares toda a reflexão fundada so bre a observação sistemática realizada pelos próprios pesquisadores. I ronia do destino, é essa definição empírica da disciplina que constituiu uma das maiores contribuições da "escola sociológica de São Paulo", que fez dos" fundamentos empíricos da explicação sociológica" o lema e o padrão de trabalho, inscrevendo as ciências sociais produzidas no B rasil entre as tendências dominantes da cena internacional. 0 que resta de sociologia quando um presidente, no exercício do mandato e no calor das movimentações de toda ordem, retoma a sua experiência imediata e a visão que a justifica como padrão analítico em ciências sociais?

Contra a heteronomia das ciências sociais, a história social das relações entre o campo político e o espaço das ciências sociais no Brasil parece fornecer poderosos antídotos, em particular contra o "fascínio" do poder político e suas artimanhas. 0 ol har sociológico, dotado das lentes forjadas pelos "pais-fundadores" e comprometido a investigar as questões mais corriqueiras dessas ciências, parece impedir de aceitar candidamente 0 "mundo encantado" dos profissionais da política.

\section{Referências Bibliográficas}

C anedo, Letícia Bicalho. (2002), “H éritage en politique, ou comment acquérir les dispositions et les compétencesnécessai res aux fonctions de représentation politique (1946-64)". C ahiers du B résil C ontemporain, 47-48: (71-119). 
CARdoso, Fernando H enrique. (1962), C apitalismo e escravidão no B rasil meridional. Rio de Janeiro, Paz eTerra.

. (1964), E mpresário industrial e desenvolvimento econômico no B rasil. São Paulo, Difusão Européia do Livro.

\& Falleto, E. (1979), D ependência e desenvolvimento na A mérica $L$ atina. R io de Janeiro, Z ahar.

. \& Soares, M . (1998). 0 mundo em português. São Paulo, Paz eTerra.

C ARdo so, I rene. (1982), A universidade da comunhão paulista. São Paulo, C ortez.

Dezalay, Y ves \& Garth, Bryan. (2002), M ondialisation de la guerre des palais. Paris, Seuil.

FArIA, Luiz de Castro. (2002), 0 liveiraV ianna: 0 autor, os livros, a obra. R io de Janeiro, Relume D umará.

Fern an des, Florestan. (1967), F undamentos empíricos da explicação sociológica. São Paulo, C ompanhia Editora $\mathrm{N}$ acional.

Garcia Jr., A frânio. (1998a), "C elso Furtado, la guerre froide et le développement du N ordeste". A des de la R echerche en Sciences Sodiales, 121-122: 52-61, mar. . (1998b), "La construction politique d'un avenir régional: C elso Furtado et la création de la Sudene". C ahiers sur le B résil C ontemporain, 33-34: 123-132.

Kowarıck, Lúcio (coord.). (1976), São Paulo, cresamento e pobreza. São Paulo, Loyola. LeO N I, B rigitte H ersant. (1997). F ernando H enrique C ardoso, o B rasil do possível. R io de Janeiro, N ova Fronteira.

LoPES, José Sérgio Leite. (1990), "H istória social da sociologia do trabalho e dos trabalhadores no Brasil". Rio de Janeiro, PPGAS/M N (mimeo).

. (2003), "Pierre Bourdieu et le renouveau des enquêtes ethnologiques et sociologiques au Brésil". AW A L , 27-28: 169-178.

Love, J. (1996), C rafting the third world. Stanford, Stanford U niversity Press.

M Ayo, M arcos Chor. (1997), A história do projeto U nesco: estudos radiais e dência no $B$ rasil. Tese de doutorado. $R$ io de Janeiro, Iuperj.

M AzZA, D ébora. (2003), A produção sociológica de Florestan F ernandes e a problemática educacional. Taubaté, C abral.

M IC elı, Sergio. (1989). H istória das dências sodiais no B rasil. São Paulo, Vértice, vol. 1.

Po Llak, M ichael. (1996), “M ax Weber, elementos para uma biografia sócio-intelec-

tual". M ana. E studos de A ntropologia Social, 2 (1-2): 85-114.

Pontes, H eloisa. (1998), D estinos mistos. São Paulo, C ia. das Letras.

To Ledo , R oberto Pompeu. (1998), 0 presidente segundo o sociólogo. São Paulo, Cia. das Letras.

W eber, M ax. (1959), L e savant et le politique. Paris, Plon. 


\section{Resumo}

Este artigo analisa a trajetória social, intelectual e profissional de Fernando H enrique C ardoso para entender os diferentes recursos sociais e disposições pessoais utilizados em sua carreira como sociólogo e em suas atividades como especialista da política. Busca demonstrar que os capitais sociais e as disposições responsáveis pelo prestígio como pesquisador e professor de ciências sociais foram distintos dos aplicados no domínio da política, permitindo sua rápida ascensão à presidência da R epública. D epois de estudar suas origens familiares, focaliza seus investimentos escolares e a escolha do ofício de sociólogo, a carreira promissora sendo bloqueada pelo golpe de 1964 . 0 exílio permitiu a extensão das atividades e o reconhecimento internacional, reinvestidos em novo concurso para a U SP; 0 AI-5 o conduzirá à dupla condição de cientista social e de um dos líderes da frente de oposições aos militares. Por fim, analisa-se a reconversão de seus recursos sociais e pessoais na profissão política. Palavras-chave: Sociologia; C ampo político;Trajetória social; C apitais sociais; D isposições.

\section{Abstract}

This article analyzes Fernando H enrique Cardoso's social, intellectual and professional trajectory in order to understand the different social resources and personal dispositions carried out in his career as sociologist or in his activities as a professional politician. It seeks to prove that the social capitals and the dispositions that might explain his prestige as researcher and professor of social sciences were very different from those required in the political domain, the ones allowing his fast rise to be the president of the R epublic. After having examined his family origins, it focuses his scholar investments and the choice of the sociologist's occupation, a promising career suddenly blocked by the 1964 military coup. The exile encouraged new initiatives and brought him international appraisal, this moment being crowned with his access to the chair of political science at the $U$ niversity of São Paulo; the AI- 5 enforced by the military rulers will enable him to assume a double condition, as social scientist and as an important opposition leader facing the military. Finally, it analyzes how he

Afrânio Garcia Jr. é sociólogo, pesquisador associado ao CNRS (Paris) e diretor do Centro de Pesquisas sobre o Brasil Contemporâneo/ $\mathrm{M}$ aison des Sciences del'H ommel E.H.E.S.S. was able to reconvert his social and personal resources into the political profession. Keywords: Sociology; Political field; Social trajectory; Social capitals; Dispositions. 